\title{
Entre el humanismo cívico y el liberalismo de izquierda
}

\author{
MARTÍN DAGUERRE* \\ Conicet (Argentina)
}

RESUMEN. Comenzaré exponiendo la crítica «humanista» al liberalismo de izquierda y analizando la respuesta a la misma que, desde esta última postura, ofrece W. Kymlicka, y destacaré sus coincidencias con el republicanismo clásico. Argumentaré luego que, aun aceptando la respuesta de Kymlicka, el liberalismo de izquierda no deja de tener dificultades a la hora de generar participación ciudadana. La diferenciación que hace entre ética y política hace que carezca de sentido la participación política en sociedades injustas. Para superar este problema, es necesario apelar -como los humanistas - al valor intrínseco de la participación, pero evitando una defensa de la participación por la participación misma, que acarrearía -como señala Kymlicka en su defensa del liberalismo- consecuencias contraintuitivas. A fin de evitar tanto los problemas del liberalismo como los del humanismo, partiré de una analogía entre relaciones de amistad y relaciones políticas, y propondré una definición de estas últimas que muestre que es posible otorgar a la participación un valor intrínseco, sin incurrir en los peligros de la apelación a indentidades religiosas, naciones o semejantes.

Palabras clave: reciprocidad, humanismo cívico, liberalismo, participación política, amistad.
ABSTRACT. I shall begin by exposing the «humanist» criticism of leftwing liberalism and analizing W. Kymlicka's left liberal response to it, while highlighting its coincidences with classical republicanism. I shall then argue that, even if we accept Kymlicka's response, leftwing liberalism is still problematic due to its difficulty in generating political participation. Liberal separation of ethics and politics renders political participation in unjust societies pointless. In order to surmount this problem, we need to resort to the intrinsic value of participation, as humanists do, while avoiding a defense of participation for its own sake, that would carry counter intuitive consequences, as shown by Kymlicka in his defense of liberalism. With a view to avoiding the problems of both liberalism and humanism, I shall draw an analogy between friendship and political relationships and propose a definition of the latter that will show we need not incur the dangers of appealing to religious or national identities or the like in order make political participation intrinsicly valuable.

Keywords: reciprocity, civic humanism, liberalism, political participation, friendship.

* Este trabajo ha sido financiado por el PICT 4-14149 de la Agencia Nacional de Investigaciones (Argentina) y por el Conicet. 
El republicanismo se ha presentado como una altemativa al liberalismo. La oposición entre ambas corrientes es obvia si entendemos por liberalismo la defensa de una concepción pluralista de la democracia, en donde la política es el resultado de la competencia de grupos de interés. Sin embargo, los republicanos han pretendido ser también una alternativa al liberalismo de izquierda defendido por John Rawls y Ronald Dworkin, y es esta oposición la que analizaré en primer lugar.

El republicanismo ha sido vinculado, directa o indirectamente, con la virtud cívica, con la participación política de los ciudadanos. Ahora bien, la participación puede entenderse como condición necesaria para mantener las libertades individuales, o como lo que le da verdadero valor a la vida de las personas. A la primera concepción se la suele llamar «republicanismo clásico», y a la segunda «humanismo cívico».

Presentaré primero la crítica «humanista» al liberalismo de izquierda. Luego analizaré la respuesta que desde esta última posición elabora W. Kymlicka, y destacaré sus coincidencias con el republicanismo clásico.

Ahora bien, aun aceptando la respuesta de Kymlicka, el liberalismo de izquierda no deja de tener problemas a la hora de generar participación ciudadana. La diferenciación que hace entre ética y política hace que carezca de sentido la participación política en sociedades injustas.

Para superar este problema, es necesario volver sobre la valoración intrínseca de la participación, lo cual nos acerca de nuevo al humanismo, pero sin caer en una defensa de la participación por la participación misma, que llevaría a conclusiones contraintuitivas, como muestra Kymlicka en su defensa del liberalismo.

Para superar tanto los problemas del liberalismo como del humanismo, tomaré la analogía entre las relaciones de amistad y las relaciones políticas, para luego ofre- cer una definición de estas últimas, y destacar entonces que no es necesario apelar a nociones religiosas, o de identidad nacional, o similares, para que la participación adquiera un valor intrínseco.

\section{El problema de la participación en el liberalismo de izquierda}

En términos de Rawls, el liberalismo asume el hecho del pluralismo ${ }^{1}$ como un rasgo ineludible de una sociedad democrática, razón por la cual aboga por la defensa de una concepción política que pueda ser aceptada por todas las concepciones comprehensivas razonables. De aquí que no pueda identificarse con la defensa de alguna concepción de vida buena.

El Estado aparece como el marco neutral en el que los ciudadanos pueden perseguir toda concepción de vida buena que no choque con el mismo. En este sentido debe entenderse la prioridad de lo correcto sobre lo bueno:

En la justicia como equidad la primacía de lo justo significa que los principios de justicia política imponen limitaciones a los estilos de vida permisibles; $y$, por consecuencia, las exigencias de los ciudadanos que pretenden seguir estilos de vida transgresores de esos límites carecen de peso ${ }^{2}$.

De modo que la concepción de justicia defendida no podrá derivarse a partir de un compromiso con alguna concepción de vida buena. Se deberá derivar, en vez, de lo que Rawls ha llamado la «posición original», una posición en la que los sujetos puestos a elegir los principios de justicia desconocen, entre otras cosas, su propia concepción de vida buena.

Para Sandel, tal planteamiento supone una concepción del sujeto según la cual éste es anterior a sus fines, ya que, para elegir los principios correctos, el yo debe poder abstraerse de cualquier meta que persiga en su vida, de cualquier relación especial que mantenga con otros sujetos. 
A este sujeto Sandel lo llama «el yo desvinculado» (unencumbered self). Esta concepción del sujeto permite pensar cierto tipo de comunidad, pero anula la posibilidad de lograr otra:

Entendidos como «yoes» desvinculados, por supuesto, somos libres de unirnos en asociaciones voluntarias, y así somos capaces de tener una comunidad en el sentido cooperativo. Lo que se le niega al yo desvinculado es la posibilidad de ser miembro de alguna comunidad unida por lazos morales anteriores a la elección: no puede pertenecer a ninguna comunidad donde el yo mismo pudiera estar en juego. Tal comunidad - llamémosla constitutiva como contrapuesta a meramente cooperativainvolucraría tanto la identidad como los intereses de los participantes, y así comprometería a sus miembros en una ciudadanía más completa de lo que el yo desvinculado puede conocer ${ }^{3}$.

No se trata sólo, para Sandel, de destacar dos modos de pensar la comunidad. La sociedad que los liberales de izquierda tienen en mente exige un conjunto de sacrificios por parte de los ciudadanos, y estos sacrificios sólo pueden esperarse si la comunidad constituye la identidad de los mismos. Por lo tanto, concluye Sandel, el liberalismo es inherentemente inestable 4 : su éxito depende de un compromiso ciudadano incompatible con una sociedad cooperativa, la cual es la única sociedad imaginable desde el esquema liberal. El tipo de sociedad que puede fomentar un Estado liberal no genera el compromiso ciudadano necesario para lograr sus fines y ser estable.

Sandel lo ejemplifica con el principio de la diferencia rawlsiano:

$\mathrm{Si}$ aquellos con quienes se me exige que comparta la suerte son, moralmente hablando, realmente otros, en vez de compañeros participantes en una forma de vida a los que mi identidad está unida, el principio de diferencia cae presa de las mismas objeciones que el utilitarismo. Su pretensión hacia mí no es la pretensión de una comunidad constitutiva cuyos lazos reconozco, sino más bien la pretensión de una colectividad concatenada a entramados a los que yo me enfrento.

Lo que el principio de diferencia requiere, pero no puede dar, es algún modo de identificar a aquellos entre los cuales las dotes que poseo se consideran adecuadamente como comunes, alguna manera de vernos a nosotros mismos como mutuamente en deuda y moralmente comprometidos desde el comienzo ${ }^{5}$.

Sólo puede esperarse una ciudadanía comprometida allí donde la comunidad constituye la identidad de los ciudadanos. Sólo si poseo un vínculo moral previo estaré dispuesto a sacrificarme por aquellos con los que me siento moralmente vinculado; $y$ tal vínculo moral previo viene dado por la pertenencia a una comunidad que me constituye.

Según Sandel:

la nación demostró ser una escala demasiado grande para cultivar la autointerpretación común necesaria para la comunidad en el sentido formativo o constitutivo. Y por eso el giro gradual, en nuestras prácticas e instituciones, desde una filosofía pública de fines comunes hasta una filosofía de procedimientos equitativos, de una política de lo bueno a una política de lo correcto ${ }^{6}$.

El fuerte sentido de comunidad se fue perdiendo a medida que las escalas de las sociedades se fueron ampliando, y el liberalismo procedimental pareció más natural que el republicanismo nacional.

\section{La respuesta de Kymlicka al humanismo cívico}

W. Kymlicka, que ha asumido la defensa del liberalismo de izquierda frente a la crítica de Sandel, presenta a ésta del siguiente modo:

1. Los estadounidenses sienten descontento hoy en día debido a la pérdida del sentido de comunidad y a la pérdida de un sentido de control sobre su destino.

2. Esta sensación de descontento sólo puede atajarse si se presta atención a las cues- 
tiones relacionadas con la identidad comunal y la virtud cívica.

3. El liberalismo procedimental no puede prestar atención ni a la identidad comunal ni a la virtud cívica debido a su compromiso con la posibilidad de revisión racional (el «yo sin trabas») y el Estado no perfeccionista («neutralidad estatal») 7

Al no aprobar que el Estado sostenga una noción particular de comunidad, el liberalismo no permite que los ciudadanos se identifiquen con él, lo cual genera un descontento que deriva en una apatía ciudadana que vuelve inestable al mismo Estado liberal.

La respuesta de Kymlicka parte de señalar que «[1]a distinción entre el bien y el derecho es una distinción entre dos tipos de justificaciones de las políticas públicas, no entre dos tipos de objetos de la política pública» ${ }^{8}$. Es un error pensar que las políticas liberales no pueden tener por objeto la virtud cívica o la identidad comunal. El hecho de que el Estado liberal no pueda apelar a una concepción de la buena vida para justificar sus políticas, no implica que el Estado no pueda tener por objeto de sus políticas algún tema en particular. El Estado liberal jamás puede promover las virtudes cívicas y la identidad nacional por el valor que tengan para la realización personal, pero sí puede hacerlo si su promoción resulta ser el mejor (o único) modo de garantizar su estabilidad:

una virtud no es un concepto del bien a menos que se justifique sobre la base de que enriquece la vida de la persona que la posee. $\mathrm{Y}$, sin embargo, ésa no es la única justificación posible para promover las virtudes cívicas, que pueden sostenerse en cambio como una precondición para la justicia hacia otros.

Lo mismo se aplica a las cuestiones de identidad comunal [...] Sabemos que es más probable que la gente haga sacrificios a favor de otros si esos otros son considerados «de los suyos»y, por consiguiente, promover un sentido de la identidad nacional robustece el sentido de mutua obligación que se necesita para sostener la justicia liberal $?$.

Si, como señala Sandel, el principio de diferencia requiere que aquellos que se rigen por él sientan que comparten una identidad común, entonces el Estado liberal tiene una razón legítima para promover un sentido de pertenencia en todos los ciudadanos.

Si el liberalismo no tiene ningún impedimento de principio para abordar la defensa de las virtudes cívicas y de una identidad nacional, $¿$ cómo quedan las diferencias con el humanismo cívico?

La línea de argumentación liberal sólo permite defender aquellas identidades comunales y virtudes que apuntalen los principios liberales. Si no pudiese esperarse que la participación política fortaleciera la sociedad liberal, no habría modo de defender al humanismo cívico, esto es, a una posición que vea en la participación política la realización de nuestra concepción de buena vida.

Ahora bien, señala Kymlicka, «[a]dmitamos [...] que sólo pudiera sostenerse una forma de vida intrínsecamente valiosa vinculada a la participación política mediante un trato injusto a los indios. ¿Podemos decir que la promoción de un concepto humanista cívico de la vida buena justifica esta injusticia?» ${ }^{10}$. La respuesta, obviamente, es no. La participación sólo puede valorarse dentro del marco dado por la justicia. En palabras de Kymlicka:

Las instituciones políticas que pretenden un poder coercitivo sobre todos los ciudadanos no deberían ser consideradas un escenario para que la mayoría dé curso a sus modos de vida intrínsecamente valiosos. La razón de ser de las instituciones políticas consiste en garantizar la justicia a todos los ciudadanos y la promoción de las virtudes republicanas debe operar en el margen que le marca este límite ".

De modo que, si lo que a Sandel le interesa es fomentar una identidad común 
que genere un compromiso cívico importante, puede lograr sus objetivos desde el liberalismo. Pero si en alguna ocasión es necesario limitar la participación en función de la defensa de las libertades individuales, entonces parece que los caminos liberal y humanista se bifurcarán.

\section{Coincidencia entre el liberalismo de izquierda y el republicanismo cívico}

Llegados a este punto, no parece existir diferencia alguna en lo referido al lugar que tiene la participación política y la identidad común, entre liberales de izquierda y republicanos clásicos como Skinner. El republicanismo ya no sería una alternativa para el liberalismo así entendido.

Liberales como Rawls, Dworkin o Kymlicka no tendrían problemas en suscribir al republicanismo, si la tesis de los republicanos es que «si deseamos asegurar nuestra libertad personal, resulta indispensable que vivamos amparados por una constitución libre, una constitución a la cual defendemos y preservamos con nuestras mejores habilidades cívicas» ${ }^{12}$.

En Liberalismo político Rawls ha sido explícito:

Entiendo por republicanismo clásico el punto de vista según el cual si los ciudadanos de una sociedad democrática quieren preservar sus derechos y libertades básicos (incluidas las libertades civiles que garantizan las libertades de la vida privada) deben también poseer en grado suficiente las «virtudes políticas» (como yo las he llamado) y estar dispuestos a participar en la vida pública. La idea es que, sin una amplia participación en la política democrática por parte de un cuerpo ciudadano vigoroso e informado, y desde luego con un retiro generalizado a la vida privada, aun las instituciones políticas mejor diseñadas acabarán cayendo en manos de quienes se proponen dominar e imponer su voluntad a través del aparato del Estado, ya por ansia de poder y gloria militar, ya por razones de clase e interés económico, por no hablar del fervor religioso expansionista y del fanatismo nacionalista. La salud de las libertades democráticas exige la activa participación de ciudadanos políticamente virtuosos, sin cuyo concurso no podría mantenerse un régimen constitucional.

Entendido de este modo el republicanismo clásico, la justicia como equidad, como variante del liberalismo político, no tiene nada fundamental que objetar ${ }^{13}$.

Si no hay divergencia en cuanto al lugar que le cabe a la participación, entonces la coincidencia es absoluta, ya que Skinner admite que en cuanto a los fines, el republicanismo es liberal. En «Acerca de la justicia, el bien común y la prioridad de la libertad» sostiene:

suscribo completamente su idea [de Rawls] de que la mejor manera de pensar la relación entre los ciudadanos individuales y los poderes del Estado es subrayar la importancia del idéntico derecho que tienen todos los ciudadanos de perseguir, en la mayor medida posible, los fines que eligieron ${ }^{14}$.

\section{Un nuevo problema del liberalismo de izquierda}

Es claro que la participación política cumple con su rol de garante de las libertades democráticas sólo si todos los ciudadanos (o la mayoría de ellos) participan. En una sociedad bien ordenada la participación de la mayoría puede esperarse no sólo porque se supone que el Estado puede promover con éxito (y legítimamente) las virtudes cívicas y una identidad comunal que aliente la preocupación por los «propios», sino porque cada ciudadano tiene motivaciones morales para participar.

En el caso de Rawls se supone que una sociedad bien ordenada da lugar al desarrollo del sentido de la justicia. En el caso de Dworkin una sociedad justa es un parámetro normativo necesario para la satisfacción de cualquier concepción de buena vida. Es normativamente inconsistente considerar que uno debe llevar una vida 
que requiere recursos que uno mismo considera que no debe tener, en el sentido de que no le corresponden en justicia. Así, una sociedad justa, al otorgarnos la cantidad de recursos que nos corresponde, nos permite elaborar una concepción de buena vida normativamente consistente.

Ya sea por nuestro sentido de la justicia o por el vínculo que establecemos entre buena vida y política, tenemos motivaciones para contribuir con nuestra parte al sostenimiento de una sociedad justa.

Ahora bien, tomemos cualquier sociedad en la que las desigualdades de riqueza estén claramente injustificadas desde un punto de vista liberal (de izquierda). Prácticamente todas las sociedades se encuentran en esta situación. La amplia mayoría de los ciudadanos considera, con razón, que nada va a cambiar a través de su participación individual. A su vez, entiende que el tiempo dedicado a tal infructuosa participación podría rendir mayores beneficios si lo vuelca a la persecución del propio plan de vida.

En estas condiciones, podemos esperar que el sujeto razonable rawlsiano se vuelque en su proyecto de buena vida, así como el ciudadano republicano de Dworkin. El sujeto razonable supuesto por Rawls sólo participará cuando cuente con la participación de los demás:

En la medida en que somos razonables, estamos dispuestos a construir el marco del mundo social público, un marco del que resulta razonable esperar que será aceptado por todo el mundo y dentro del cual todos podrán actuar, en el bien entendido de que se puede confiar en que todos harán lo mismo. Si no podemos confiar en ello, entonces podría ser irracional o autoinmolatorio actuar a partir de esos principios ${ }^{15}$.

De aquí que una sociedad bien ordenada sea estable. Si me encuentro en una sociedad en la que todos cumplen con su parte, me veo motivado a cumplir con la mía. Pero esta motivación no existe antes de que la sociedad esté bien ordenada: «[1]a estabilidad está garantizada por una motivación adecuada suficiente, una motivación adquirida en el contexto de instituciones justas» 16.

Por su parte, Dworkin señala que el ciudadano republicano es un ciudadano integrado, esto es, siente que su vida no es ajena a los resultados logrados por la comunidad. Pero aclara:

El argumento de la integración no supone que el buen ciudadano se preocupará por el bienestar de sus congéneres, sino que afirma que debe preocuparse por su propio bienestar y, que en virtud de dicha preocupación, debe interesarse por la vida moral de la comunidad de la cual forma parte ${ }^{17}$.

Si bien, como señalamos, la justicia es un parámetro normativo, Dworkin destaca que es un parámetro blando, no duro, esto es, una circunstancia que, en caso de no darse, afecta la realización de nuestra concepción de buena vida, pero no la anula ${ }^{18}$ Siendo esto así, en el marco de una sociedad injusta no puede esperarse que los ciudadanos republicanos participen políticamente, en la medida en que no puede preverse que tal participación resulte exitosa.

Dado que en una sociedad injusta no se da, por hipótesis, una participación política virtuosa y masiva ${ }^{19}$, no puede decirse que la participación esté cumpliendo su rol estratégico, y seguirá sin cumplirlo aun si uno, individualmente, aporta lo suyo. Cada ciudadano liberal-republicano tomado individualmente carece de motivación para dedicar una parte considerable de su tiempo a los asuntos públicos. Sin embargo, si todos estos ciudadanos participasen por el valor intrínseco de la participación misma, los efectos deseados tendrían la posibilidad de darse.

No debe confundirse este problema con el del dilema del prisionero. No se trata de que, hagan lo que hagan los demás, me conviene no cooperar. Si yo pudiese contar con la cooperación de los demás, 
mi mejor opción sería cooperar. Pero dado que me encuentro en una sociedad no cooperativa, hasta que no se dé cierto umbral de cooperación no tengo razones para cooperar. Pero este planteamiento no permite que nos acerquemos al umbral de cooperación, y aquí está el problema.

Nos encontramos, pues, con la siguiente disyuntiva: o asumimos un humanismo cívico que puede llevarnos a cometer injusticias, o le damos a la participación un carácter instrumental que no nos permite superar las injusticias actuales. Para superar esta disyuntiva considero necesario retomar el «humanismo cívico», pero desde una mirada en algún sentido más amplia. Intentaré ahora delinear esta alternativa.

\section{Relaciones políticas y buena vida}

Kymlicka, en su respuesta a Sandel, señala lo siguiente:

Sandel escribe a menudo como si la expresión «concepto de la vida buena» abarcase todas las creencias normativas. Sin embargo, un concepto de vida buena es simplemente eso - es decir, una noción sobre lo que hace que la vida de uno sea buena, o de aquello que hace que vaya mejor la propia vida-. Es un concepto relacionado con aquello que hace que valga la pena vivir nuestra vida, con las actividades, las relaciones y los bienes que hacen que la propia vida sea más plena y rica, más gratificante y satisfactoria [...] El Estado debe dejar los juicios sobre la vida buena a los individuos y debería tratar en cambio de garantizar que los individuos dispusieran de un contexto libre y justo en el que realizar esos juicios ${ }^{20}$.

Ahora bien, si el concepto de vida buena incluye las relaciones que hacen que la propia vida sea más satisfactoria, entonces antes de determinar el rol del Estado debemos resolver si las relaciones políticas (encarnadas en la figura del Estado) forman parte, o no, de dicho concepto. ¿Qué razón tenemos para, a priori, pensar las relaciones políticas como ajenas a la concepción de buena vida de los ciudadanos? ¿Por qué no podemos considerar que entre las relaciones que dan valor a nuestra vida se encuentran las relaciones políticas?

Tendemos a descartar esta posibilidad porque entendemos que, por ejemplo, las ideas religiosas pueden formar parte de la concepción de vida buena de una persona, y no de la de otras, y entendemos que aun así es posible y deseable que convivan en una misma sociedad política. Creemos que es razonable que una persona desee tener una relación especial con quienes comparten sus ideas religiosas, y que considere que tal relación forma parte de lo que significa para ella llevar una vida buena, $y$, sin embargo, estamos convencidos de que las diferentes ideas religiosas (en la medida en que sean razonables en el sentido rawlsiano) no impiden la buena convivencia política. Y obviamente, para que esta convivencia sea posible, no debe organizarse desde ninguna concepción religiosa.

Tal como esto es así con respecto a las ideas religiosas, también lo es, se considera, con respecto a cualquier otra idea definitoria de una concepción de vida buena. La concepción de vida buena de una persona puede diferir en cualquier aspecto de la concepción de vida buena de otra, y, sin embargo, ambas pueden conformar la mejor sociedad política.

Pese a su atractivo, considero que el argumento va demasiado rápido. Que el Estado no puede imponer una religión puede resultarnos totalmente aceptable, pero consideraciones de este tipo sólo nos permiten concluir que la relación política no puede definirse apelando a tales ideas religiosas. Y lo mismo puede resultarnos chocante que se desee introducir en la política consideraciones sexuales o algún burdo perfeccionismo. Sin embargo, intentaré mostrar que no toda idea que forme parte de una concepción de vida buena debe descartarse al analizar el papel de la política. 


\section{Rasgos de la relación de amistad}

En su ensayo «Propósitos cruzados: el debate liberal - comunitario» ${ }^{21}$, Charles Taylor diferencia tres tipos de bienes que se persiguen colectivamente. Por un lado, existen bienes convergentes, como pueden ser la seguridad policial o el contar con un cuerpo de bomberos, que sólo son accesibles a través del aporte de todos, pues nadie podría solventarlos individualmente. A estos bienes se los llama colectivos sólo por el modo en que cada uno puede proveerse de ellos. Por otro lado, tenemos lo que Taylor denomina bienes "mediatamente comunes»: si bien uno puede disfrutar de una película sin estar acompañado, el hecho de verla con su pareja posiblemente genere una experiencia diferente. Aquí el bien es colectivo en el sentido de que la participación de más de un individuo modifica el beneficio obtenido de ese bien. Finalmente, están los bienes «inmediatamente comunes», en donde el valor está constituido, en su totalidad, por el hecho mismo de compartirlo. Ejemplo de este último tipo de bienes es la amistad.

Taylor considera que una sociedad libre necesita compartir un bien de este último tipo, y de ahí su defensa del patriotismo, de un sentimiento de destino compartido que tiene valor en sí mismo. Si bien no me parece atractiva su defensa del patriotismo, sí me parece interesante retomar cierta analogía entre la amistad y las relaciones políticas, en tanto bienes inmediatamente comunes, analogía que no implica caer en una posición comunitarista.

Tomemos una relación de amistad íntima. Es normal encontrar este tipo de relación entre personas con diferentes ideas religiosas, orientación sexual, etc. Difícilmente pueda negarse que personas con diferentes ideas religiosas pueden lograr una excelente relación de amistad. Que el bien no esté constituido por el compartir tales ideas no quiere decir, obviamente, que la consolidación de tal relación de amistad no forma parte de la concepción de vida buena de los amigos. De modo que la amistad no depende de la coincidencia en ningún tipo particular de ideas, por más que ocupe un lugar importante en una concepción de vida buena.

Pero si bien no es necesario que todas las relaciones de amistad coincidan en el mismo conjunto de ideas sustantivas, podría sostenerse (para mantener la analogía comunitarista) que toda relación de amistad necesita coincidir en al menos un conjunto de ideas, sean estas religiosas, estéticas, o de cualquier otro tipo.

Hasta aquí, entonces, no habría diferencia con el planteamiento comunitarista, en tanto señala que lo que una nación requiere es algún tipo de patriotismo, lo cual no exige la defensa de un patriotismo en particular. Si bien no es necesario que todas las comunidades coincidan con el mismo conjunto de ideas, sí es necesario que cada comunidad coincida en un grupo particular de ideas que definan su identidad.

Las diferencias aparecen cuando destacamos ciertos aspectos en común que deben tener las relaciones de amistad, y desarrollamos sus consecuencias para la política. Si bien los amigos pueden disentir en todos los puntos referidos, al menos dos rasgos no pueden faltar en la relación. En primer lugar, para que se dé la relación de amistad debe darse una disposición recíproca a un conjunto de acciones. Se supone, por ejemplo, que al encontrarse uno en problemas, espera de los amigos un tipo de ayuda que no puede exigirse a un desconocido ${ }^{22}$; si quien es considerado un amigo no responde con la acción esperada, la relación se replantea, y podrá concluirse que la relación no era tan íntima, o que simplemente no existía una relación de amistad con tal persona.

Pero no es la acción en sí misma lo determinante, sino la disposición a realizarla. Quizá uno no necesite nunca que le hagan un favor, pero eso no quita que suponga en los amigos la disposición a 
hacérselo si fuera necesario. Y cuando uno hace un sacrificio por un amigo, espera que su amigo haga algo similar por él sólo si resulta necesario. La ayuda no se concibe como un préstamo, que uno espera cobrar más adelante; la ayuda es la actualización de una disposición que valoramos tener (en la medida en que haya reciprocidad). La realización de tales acciones no se entiende desde un punto de vista estratégico, como medio para un fin diferente de la relación misma. La acción forma parte del fin mismo.

Imaginemos una persona que se encuentra desconsolada por x razón. Puede que un amigo suyo no sepa de qué modo ayudarla a superar su estado, o quizá piense que sólo el tiempo puede «curarla». Aun así, se supone que no corresponde que se desentienda de la situación. Uno puede actuar de un modo que, supone, no será la solución al problema, por el mero hecho de mostrar que tiene la disposición; así, sucede que uno hace lo que un amigo le pide, más allá de que uno considere que tal acción no es la solución al problema del amigo. Obviamente, esto no quita que uno busque el mejor modo de ayudar, pero cuando no está clara la solución, aun así uno actúa de algún modo, y lo hace intentando dejar en claro que su disposición existe.

Ahora bien, se supone que los amigos valoran esa disposición recíproca (lo que constituye a la amistad en un bien común), $y$ aquí podemos introducir el segundo rasgo. La valoración supone la autonomía de los miembros de la relación. La valoración debe ser autónoma; si la valoración proviene de engaños, carencia de información, etc., no podemos hablar de una relación de amistad. No me extenderé en este punto, pues creo que resulta intuitivamente claro.

\section{Definición de la relación política}

Con todo esto presente, volvamos sobre la cuestión de si las relaciones polí- ticas deben conformar un marco neutral en el que cada ciudadano pueda desarrollar su concepción de la vida buena, o deben formar parte de la concepción de vida buena de todos los ciudadanos. ¿Puede pensarse a la conciudadanía como un bien común que incluya la valoración de cierta disposición recíproca? ${ }^{23}$.

Evidentemente no podemos pretender una disposición similar a la que se da entre amigos o en una relación de pareja. Pero, por otro lado, para que la relación sea un bien común, debe existir alguna disposición que permita diferenciarla de un mero modus vivendi, en donde cada uno da hasta donde le conviene. Desde esta última perspectiva, la relación no pasa de ser un bien convergente, en términos de Taylor.

$\mathrm{Si}$ bien valoramos las relaciones de pareja y de amistad, y consideramos que tales relaciones «hacen que la propia vida sea más plena y rica, más gratificante y satisfactoria», debemos ver ahora si podemos valorar de un modo análogo las relaciones políticas, que implican a personas que quizá no veremos jamás, y con las que no compartimos gustos, ideas religiosas, etc. ¿Qué disposición podemos esperar de tales personas, que lleve a que valoremos formar un colectivo con ellas?

En principio, no puedo valorar formar parte de un colectivo cuyos miembros son indiferentes a mi estado de indigencia, mis problemas de salud, mi falta de vivienda. Evidentemente, si tal colectivo tiene un valor para mí, se debe a que no tengo mejor opción que vivir en esa sociedad. Esta sociedad no pasaría de ser un modus vivendi. Es claro que puedo valorar una relación con personas con las que comparto, por ejemplo, un gusto por cierta literatura; me satisface intercambiar información con ellos, reunirme en congresos a discutir sobre alguna interpretación de una obra, etc., y no espero que tales personas se preocupen especialmente por mis problemas económicos. Pero aquí el valor de la relación se deriva del valor de una actividad 
que se comparte, y al hablar de política estamos hablando de una relación con personas con las que probablemente no me veré jamás, y con las que puedo no compartir ningún gusto, concepción religiosa, etc.

Supongamos una sociedad con un desarrollo económico suficiente como para que todos los miembros se alimenten óptimamente. Supongamos que, sin embargo, un porcentaje de la población no tiene acceso a una canasta alimentaria básica. Una persona que forme parte de este sector de la sociedad, ¿puede valorar la relación política que tiene con aquellos que se oponen a una redistribución de los bienes indispensables para él y su familia? Uno puede entender que prefiera estar en esa sociedad a cualquier otra opción que tenga, pero no por eso la relación política tendrá un valor intrínseco. Tal sociedad sólo será un modus vivendi.

Ahora bien, no sólo no puede, tal persona, valorar intrínsecamente su relación política con quienes se oponen abiertamente a la redistribución, sino con todos los que se mantienen al margen del conflicto. Tomemos a un empleado con un ingreso suficiente como para tener acceso a una amplia cantidad de bienes, sin ser ésta una cantidad exagerada. Este empleado posee una familia, concurre cotidianamente a su trabajo, se reúne con sus amigos $\mathrm{y}$, en el terreno público, se limita a pagar los impuestos (lo que contribuye, probablemente, a mantener o profundizar la distribución injusta de los recursos). Tal persona, podemos suponer, no se opone a una redistribución de los recursos, pero tampoco hace nada por modificar la actual distribución o por mostrarse contraria a la misma. ¿Qué es lo que un indigente puede valorar de la relación política que de hecho lo une con tal ciudadano? Considero que nada puede hacernos valorar una relación política con personas que no se ven motivadas a hacer algo con el fin de que uno salga de su estado de indigencia.
De modo que para que la relación pueda valorarse, debe darse, al menos, una disposición recíproca a proteger la vida del otro, lo cual puede traducirse en una disposición recíproca a actuar con el fin de que todos los miembros tengan las necesidades básicas satisfechas. $\mathrm{Y}$ como la valoración de la relación supone la autonomía de los miembros, también deberá existir una disposición a trabajar con el fin de lograr las condiciones de la autonomía.

\section{Diferencias con las anteriores posturas}

Si consideramos que tal relación es valiosa, que conformar tal colectivo vuelve a nuestra vida más gratificante $y$ satisfactoria, tenemos una razón para oponernos a los comunitaristas o a los liberalnacionalistas, en la medida en que supeditan la participación política a la consecución de mejoras para aquellos que comparten algo más que la disposición aquí destacada. Como no pueden justificar la participación política, y consideran que ésta es necesaria, apelan a rasgos arbitrarios que dan identidad, incluyendo en la sociedad a personas que, por ejemplo, comparten nuestro pasado, y excluyendo a otras que, sin este pasado común, comparten un ideal de sociedad.

Esto da lugar a que ciudadanos de países desarrollados vuelquen su energía a solucionar problemas menores de su país, antes que considerar la situación de los movimientos sociales de otros países que luchan por cuestiones básicas, y en condiciones muy adversas. Desde la posición que he venido desarrollando, resulta relevante la disposición y no la nacionalidad. Así, es claro que me sentiré más comprometido con movimientos sociales extranjeros, cuyas reivindicaciones estén en sintonía con la relación política aquí defendida, que con cualquier problema que puedan tener conciudadanos que no reflejen la disposición requerida. 
Si valoramos tal relación, entonces, y consideramos que formar parte de un colectivo tal hace a nuestra concepción de vida buena, no es necesario agregar ningún rasgo más para generar participación, como sí resulta necesario para comunitaristas y liberal-nacionalistas.

Podríamos decir que ésta es la relación más básica, más tenue, que exige la mínima disposición que puede exigirse, pero que por lo mismo tiene mayor alcance, ya que tal relación puede establecerse con personas con las que diferimos en prácticamente todo y con las que no tenemos un trato cotidiano. Si formar parte de un colectivo en el que los miembros tienen esa disposición hace que nuestra vida sea «más plena y rica, más gratificante y satisfactoria», podemos decir que la búsqueda de la misma, y su posterior consolidación, debe guiar la conformación de un Estado. Cualquier relación más estrecha (de amistad o de pareja, por ejemplo) debe definirse de modo que no se contraponga con la relación política ${ }^{24}$, ni justifique una violación sistemática de la misma ${ }^{25}$. Caso contrario, nos hallaríamos ante una contradicción normativa: no podemos perseguir bienes, relaciones o experiencias que contribuyan a nuestra realización personal, que consideremos que debemos lograr, a la vez que perjudican la relación política que consideramos deseable lograr.

Llegados a este punto, las diferencias con el humanismo cívico resultan claras. No se trata de defender la comunidad por la comunidad misma, ni la participación por la participación misma, sino un tipo particular de comunidad en el marco de la cual la participación sí adquiere un valor intrínseco, no estratégico. Recuérdese el ejemplo de la persona que no sabía cómo ayudar a su amigo angustiado. En el caso político podemos verlo del siguiente modo. Supongamos que un grupo de personas que carecen de lo mínimo deciden manifestarse frente a la Casa de Gobierno. Supongamos, además, que la posibilidad de que se los escuche sea nula, y que no se vea ninguna estrategia que lleve a un cambio en la situación de estas personas. En este contexto, no hay nada que motive a un ciudadano liberal de clase media a participar políticamente para generar el cambio. Sin embargo, desde mi perspectiva, ver el modo de sumarse, participar de la protesta, forma parte de mi realización. Por lo tanto, tengo motivos para participar, y posiblemente, en la medida en que tal postura se difunda, los cambios tendrán mayores posibilidades de darse.

Tomemos ahora el caso que Kymlicka presentaba para mostrar las consecuencias contraintuitivas del humanismo. Su pregunta era: ¿podemos decir que la promoción de un concepto humanista cívico de la vida buena justifica tratar injustamente a los indios, esto es, podemos cometer injusticias si las mismas nos garantizan la mayor participación política de la gente? Lo que podemos decir ahora es que no es la participación en sí lo que importa, sino la participación en cierta relación. Si los indios no tienen la disposición que nos parece defendible (una disposición a hacer lo necesario por que todos los que tienen la misma disposición tengan las necesidades básicas satisfechas), y poseen recursos indispensables para nuestra supervivencia, estará justificado hacer lo necesario para satisfacer nuestras necesidades básicas. $\mathrm{Si}$ tienen la misma disposición, formaríamos todos una sociedad, y buscaríamos los medios para que todos tengamos las necesidades básicas cubiertas.

¿Cuáles son las diferencias con el liberalismo de izquierda?

Si la confrontación la viésemos desde la perspectiva del Estado de una sociedad bien ordenada, no veríamos muchas diferencias. Para el liberalismo la participación es condición necesaria del sostenimiento de las libertades, y en mi propuesta la autonomía de los ciudadanos es condición necesaria del bien común ${ }^{26}$. En ambos modelos veríamos participación 
política y autonomía. A su vez, ambos modelos bregarían por que nadie tuviese las necesidades básicas insatisfechas.

Las diferencias salen a la luz, no en una sociedad bien ordenada, en donde encontramos libertad y participación, sino en una sociedad injusta. Si tomamos un ciudadano que, por las razones que sean, mantiene un conjunto de libertades, y a la vez su participación no garantiza ningún cambio en las libertades de los demás, pero posiblemente lleve a perder o dejar de disfrutar algunas de las libertades que tiene, ambos modelos ofrecen recomendaciones diferentes. Uno lleva a participar, y el otro no.

\section{Conclusiones}

Como hemos visto, el problema del liberalismo no pasa por no poder darle lugar a la participación política en su esquema. La división que establece entre ética y política, entre concepción de buena vida y justicia, no implica que desde la política no pueda impulsarse la defensa de un sentimiento de pertenencia al colectivo, que lleve a los ciudadanos a participar en su defensa. De aquí que el republicanismo clásico no signifique innovación alguna al planteo liberal.

Sin embargo, la división entre ética y política sí tiene graves consecuencias en el marco de una sociedad injusta. Si mi vida tiene posibilidades de ir bien, siempre y cuando no sea yo el afectado por las injustas desigualdades y por las arbitrariedades manifiestas, y si además no considero que las acciones públicas que puedo realizar puedan modificar la situación de injusticia, aunque sí pueden quitarme un tiempo importante para dedicarme a mi proyecto personal, nada hay que justifique mi participación política.

Por lo demás, no cuesta mucho convencerse de que la participación de uno no garantiza ningún cambio, y sí garantiza una pérdida de tiempo que resulta muy valioso volcado a los asuntos personales.

El liberalismo, entonces, a pesar de sus muchos atractivos, parece descansar sobre una base incorrecta, al menos si consideramos que la postura política normativa que defendemos debe generar las motivaciones necesarias para su propia consecución.

Pero este problema del liberalismo no debe llevarnos a defender la participación política por la participación misma. Como bien señala Kymlicka, no resulta aceptable fomentar el compromiso ciudadano sin tener consideración alguna por las minorías. Y éste será siempre el resultado, sì consideramos que es necesario compartir rasgos fuertes para que las personas se vean motivadas a actuar por el bien común de quienes comparten tales rasgos.

La propuesta aquí defendida no parte de la diferenciación liberal de la ética y la política, sino que considera que las relaciones políticas forman parte, como las relaciones de pareja o de amistad, de todo aquello que hace a nuestra vida más plena. Siendo esto así, intentaremos cultivar estas relaciones, más allá del contexto en que nos encontremos, y la participación política siempre tendrá sentido. No tener una perspectiva de éxito no lleva a desentendernos de lo público.

Sin embargo, para no caer en los defectos de un humanismo cívico intolerante, la relación política defendida ha sido la constituida por la valoración de la disposición recíproca de los miembros a satisfacer las necesidades básicas de todos ellos. Todos aquellos que valoren tal relación, formar parte de un colectivo con tal disposición, tienen razones para participar políticamente en su defensa, sin que intervengan en la justificación de la participación ideas religiosas, identidades nacionales, etc.

Quiero destacar, por último, que puede esperarse una amplia aceptación de la relación así definida, si resultan correctos los estudios tomados por S. Bowles y H. Gintis ${ }^{27}$, a partir de los cuales destacan la existencia de dos motivaciones humanas básicas: la reciprocidad fuerte y la generosidad de las necesidades básicas. 


\section{NOTAS}

1 «El liberalismo político parte del supuesto de que, a efectos políticos, una pluralidad de doctrinas comprehensivas razonables pero incompatibles es el resultado normal del ejercicio de la razón humana en el marco de las instituciones libres de un régimen constitucional democrático». J. Rawls, Liberalismo político, Barcelona, Crítica, 1996, p. 12. Tomo la posición de Rawls para definir al liberalismo, ya que los autores republicanos a los que me referiré dirigen sus críticas principalmente a este autor.

2 J. Rawls, op. cit., p. 206

3 M. Sandel, «La república procedimental y el yo desvinculado», en F. Ovejero, J. Martí y R. Gargarella (comps.), Nuevas ideas republicanas, Barcelona, Paidós, 2004, p. 82

4 En el mismo sentido se dirige la crítica de Alasdair MacIntyre en Tras la virtud: «[e]n cualquier sociedad en que el gobiemo no expresa o representa a la comunidad moral de los ciudadanos, sino un conjunto de convenios institucionales para imponer la unidad burocrática a una sociedad que carece de consenso moral auténtico, la naturaleza de la obligación política deviene sistemáticamente confusa». A. Macintyre, Tras la virtud, Barcelona, Crítica, 2001 .

5 M. Sandel, op. cit., p. 86.

6 Ibid., p. 90.

7 W. Kymlicka, «Igualitarismo liberal y republicanismo cívico: ¿amigos o enemigos?», en F. Ovejero, J. Martí y.R. Gargarella (comps.), op. cit., p. 213.

8 lbid., p. 218

9 Ibid., pp. 216-7

10 Ibid., p. 222.

11 Ibid., p. 224

12. Q. Skinner, «Acerca de la justicia, el bien común y la prioridad de la libertad», en La Política, 1996, p. 147.

is J. Rawls, op. cit., pp. 239-40.

14 Q. Skinner, op. cit., p. 141.

i5 J. Rawls, op. cit., p. 84 (las cursivas son mías).

16 Ibid., p. 174 (las cursivas son mías).

17 R. Dworkin, La comunidad liberal, Santafé de Bogotá, Universidad de los Andes y Siglo del Hombre Editores, 1996, p. 163.

18 Un parámetro normativo es duro cuando fija una condición esencial. Ver R. Dworkin, Etica privada e igualitarismo político, Barcelona, Paidós, 1993. pp. 133 y ss. Dworkin no sólo acepta que la justicia es un parámetro normativo blando, sino que admite que una persona «podría incluso, en contados casos, tener una vida mejor que la que habría tenido en una sociedad perfectamente justa [...] algún genio financiado por una fortuna injusta -Miguel Ángel, por los Medici- puede conseguir una vida mejor que cualquiera que viviera en un Estado más justo» (p. 140).

i9 Se supone que tal participación daría lugar a una sociedad justa.

20 W. Kymlicka, op. cit., p. 219.

21 Ch. Taylor, «Propósitos cruzados: el debate liberal-comunitario», en N. Rosenblum (dir.), El liberalismo y la vida moral, Buenos Aires, Nueva Visión, pp. 177-201.

${ }^{22} \mathrm{Y}$ se supone que la ayuda esperada es una que quien la demanda estaría dispuesto a dar.

23 Diferente de la disposición a cumplir con la ley, ya que mi intención es abordar el caso de una sociedad injusta.

${ }^{24}$ Por ejemplo, un amigo no puede pretender que uno esté dispuesto a ayudarlo en cuestiones que no son de máxima urgencia, mediante acciones que implican afectar la satisfacción de las necesidades básicas de los conciudadanos.

${ }^{25}$ En ciertos momentos puede resultar justificado que uno se vuelque en sus relaciones familiares o de amistad, pero se supone que tal alejamiento de las cuestiones políticas se debe a situaciones especiales. $\mathrm{Si}$ el alejamiento fuese permanente, debería ponerse en cuestión la existencia de la disposición que la política exige.

${ }^{26}$ Cabe aclarar, sin embargo, que la participación (para el liberalismo) y la autonomía (en la propuesta aquí presentada) son condición necesaria en distintos sentidos. La participación se entiende como condición necesaria en tanto medio indispensable para otra cosa (el mantenimiento de las libertades). La autonomía resulta ser condición necesaria en tanto parte del conjunto, esto es, sin ella no se da el bien. Es inconcebible buscar otro medio para la consecución del fin.

27 Véase S. Bowles y H. Gintis, « ¿Ha pasado de moda la igualdad? El Homo reciprocans y el futuro de las políticas igualitaristas», en R. Gargarella y F. Ovejero (comps.), Razones para el socialismo, Barcelona, Paidós, 2001, pp. 171-194. 